\title{
Criatividade e pensamento crítico*
}

\author{
Gaëtan Tremblay**
}

\section{Resumo}

Neste breve artigo, com base em uma análise dos recentes discursos acadêmicos e políticos sobre a criatividade, apresenta-se uma reflexão teórica sobre a necessária articulação dialética do pensamento crítico e criativo em estudos de Comunicação. Em uma primeira etapa, são questionados os pressupostos com o objetivo de construir um novo paradigma social e econômico baseado na criatividade. Coloca-se em dúvida, em particular, as hipóteses teóricas e metodológicas de Richard Florida sobre a emergência de uma classe criativa. Em uma segunda etapa, é mostrado como é fácil para os políticos que promovem a criatividade como um valor positivo tornar-se uma pedra angular no desenvolvimento da sociedade da informação. Como conclusão, destaca-se a renovação do pensamento crítico como um complemento necessário da valorização do processo criativo nos estudos de Comunicação.

Palavras-chave: Criatividade. Espírito critico. Indústrias culturais. Ciências da Comunicação. Estratégias políticas.

\section{Creative and critical thinking}

\section{Abstract}

In this short paper, based on an analysis of recent academic and political discourses on creativity, is develops a theoretical reflexion on the necessary dialectical articulation of creative and critical thinking in communication studies. In a first step, are questions the assumptions aiming to build a new social and economic paradigm based on creativity. It doubts, in particular, Richard Florida's theoretical and methodological hypotheses regarding the emergence of a creative class. In a second step, is showing how it is easy for politicians to promote creativity as a positive value making it a corner stone in the development of the information society. As

\footnotetext{
* Texto apresentado no PANAM 2010 (Colóquio Panamericano de Comunicação), Mesa "O Espírito dos Novos Tempos -os paradígmas do Século XXI", dia 3 de dezembro de 2010, Brasilia-DF, Brasil.

** É professor doutor de ciências da Comunicação, Faculdade de Comunicação, da Université du Québec à Montréal. É co-fundador do grupo de pesquisa interdisciplinária sobre Comunicação, indústrias culturais e sociedade da informação (GRICIS). Foi o primeiro presidente eleito da Canadian Communication Association, em 1980. Tem publicado 19 livros coletivos e mais de 150 papers em revistas acadêmicas em Francês, Inglês, Espanhol e Português. Montreal-Canadá. E-mail: gje_tremblay@yahoo.ca
} 
a conclusion, it is showing that the renovation of critical thinking as a necessary complement of the promotion of creative process in communication studies.

Key words: Creativity. Critical thinking. Cultural industries. Communication studies. Political strategies.

\section{Creatividad y pensamiento creativo Resumén}

Este breve artículo, basado en un análisis de los recientes discursos académicos y políticos en la creatividad, presenta una reflexión teórica sobre la necesaria articulación dialéctica del pensamiento creativo y crítico en los estudios sobre Comunicación. En una primera etapa, los supuestos son cuestionados con el fin de construir un nuevo paradigma basado en la creatividad social y económica. El pone en duda, en particular, los supuestos teóricos y metodológicos Richard Florida en el surgimiento de una clase creativa. En un segundo paso, se muestra lo fácil que es para los políticos que promueven la creatividad como un valor positivo para convertirse en una piedra angular en el desarrollo de la sociedad de la información. En conclusión, es expuesta una renovación del pensamiento crítico como un complemento necesario de la apreciación del proceso creativo en los estudios sobre comunicación.

Palabras clave: Creatividad. Espíritu critico. Industrias culturales. Ciencias de la Comunicación. Etrategias políticas.

\section{Introdução}

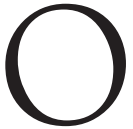

presente artigo não se propõe a falar de tecnologia nem de prospectiva do mundo das empresas. De todo jeito, as previsões são muito aleatórias. Se propõe a expor ideias, teorias e metodologias. $\mathrm{O}$ eixo principal refere à importância, por um lado, da criação e da intuição e, por outro lado, à necessidade do pensamento crítico e da metodologia científica. Como introdução, formularemos três perguntas.

Uma primeira pergunta: Quando começa um novo século? Corresponde a um novo espírito o inicio de um novo século? $\mathrm{O}$ famoso historiador Eric Hobsbawm afirma que a divisão da história em grandes períodos não corresponde exatamente com o inicio dos séculos. Por exemplo, segundo ele, o século 19 começa com a Revolução francesa de 1789 e vai até á Primeira Guerra Mundial de 1914-1918. O século 20 é mais breve e acaba com a caida do muro de Berlim. Então, para ele, o século 21 começou com dez anos de antecedência sobre o calendârio. 
Uma segunda pergunta: Se produzem novos paradigmas no século 21? A palavra "paradigma" significa modelo, padrão. Uma representação do mundo, uma maneira de ver as coisas. Crenças e verdades compartilhadas por um grupo de pessoas.

O conceito evoca a epistemologia de Thomas Kuhn. Em seu livro The Structure of Scientific Revolutions (1957, p.176) apresenta a concepção de que "a paradigm is what the members of a scientific community share, and, conversely a scientific community consits of men who share a paradigm”. Então, uma mudança de paradigmas é uma mudança de grande tamanho que não acontece cada dia nem cada década.

Uma terceira pergunta: Aparecem novos paradigmas nas ciências da Comunicação? Na minha opinhão, não tem certeza. Sem dúvida, se manifestam mudanzas. Mais estas não sempre introduzem "novos paradigmas". Porém, quais seriam os novos paradigmas que se destacam? Na área da Comunicação, ha uma tendência á inflação verbal. Se fala facilmente de revolução, de nova generação, de mutação. Parece mais prudente evitar a ênfase. Então, falaremos da criatividade que uns autores apresentam como uma nova abordagem da economia e da sociedade, sem pretender com certeza que representa um novo paradigma. Em seguida, colocamos perguntas a este modelo e argumentamos a favor de um pensamento crítico que me parece tanto necessário para o desenvolvimento das ciências da Comunicação.

\section{A criatividade como base de uma nova abordagem da economia e da sociedade}

Desde o início, o conceito de indústrias criativas se refere ao desenvolvimento de uma política econômico-cultural. Para os Mapping Documents do Reino Unido, onde tomou forma, ela reflete principalmente a busca duma posição no mercado global, baseada numa extensão do setor tradicional das indústrias culturais abrangendo novos setores como o digital, a moda e a publicidade. No caso do relatório da UNCTAD (2008), exprime o desejo de justificar a prorrogação dessa política em todo o mundo por meio da integração no setor cultural, a produção relacionada com o design e os 
ofícios artesanais tradicionais. Dada a dificuldade de identificar com precisão o novo setor de indústrias criativas, o governo britânico já está contestando essa orientação política. Além disso, a falta de credibilidade dos dados estatísticos em que se basea (ver Tremblay 2009) põe em dúvida sua difusão em escala planetária.

$\mathrm{Na}$ França (e na União Europeia), o conceito tem florescido. Na América do Norte, ele tem tido algum sucesso, mas sem causar o mesmo entusiasmo. Como explicar esta paixão em favor das indústrias criativas? Devemos vê-la como outra moda passageira ou o começo de uma reorientação das políticas econômicas e culturais nas sociedades de informação e nas economias do conhecimento? A economia criativa, que foi rapidamente induzida pelo crescimento das indústrias criativas, é apenas a manifestação mais recente da economia da informação ou economia do conhecimento, não é? Talvez, mais podemos notar, no entanto, uma diferença importante entre as teorias baseadas na criatividade e as da sociedade da informação: no primeiro caso, a tecnologia não é considerada como no segundo. O fator principal de desenvolvimento, só é um fator para atrair a classe criativa em um determinado território (ver os três T do Flórida: o talento, a tolerância, a tecnologia).

As indústrias criativas são, portanto, parte de uma cadeia conceitual de criatividade que por sua vez chama um grupo social (Creative Class), um setor industrial (indústrias criativas), territórios (Cidades Criativas) e a economia inteira de uma sociedade (Economia Criativa). Então, a criatividade encontra-se na interseção de uma teoria do capital humano, de uma política, de uma reestruturação industrial e de uma estratégia de Comunicação. No início de 2000, os especialistas da economia regional questionaram «o papel da cultura na reconstrução econômica de espaços urbanos e questionaram o seu lugar na dialética criatividade / território» (ROY-VALEX, 2010, p.65). Então, em um curto espaço de tempo, a criatividade irá experimentar uma popularidade sem precedentes entre os tecnocratas e personagens políticos. Por que essa paixão pela criatividade?

\section{A classe criativa segundo Richard Florida}

Criatividade se refere à capacidade dos indivíduos ou grupos para criar, inventar, imaginar algo novo. Uma rápida pesquisa no 
site do Centro Nacional de Recursos Textuais e Lexicais nos diz que a palavra foi emprestada do Inglês, no início dos anos 70, por psicólogos sociais, a quais logo se juntaram linguistas. Depois o conceito registrou um estrondoso sucesso no meio empresarial como evidenciado pelos numerosos títulos encontrados nas prateleiras de livrarias e bibliotecas públicas.

Desde o início dos anos 2000, um autor, Richard Florida, se destaca da multidão. Seu livro publicado em 2002, The Rise of the Creative Class, tornou-se um best-seller e uma referência para os empresários e líderes políticos. $\mathrm{O}$ autor aproveitou no mundo midiático e na consulta. Presente na internet, mídia pela qual é possível aprender sobre suas operações e suas aparições, ele viaja em todas partes do mundo, repetindo a sua boa notícia para todos aqueles que estão dispostos a pagar para ouvi-la. A mensagem do professor Flórida é relativamente simples: nas sociedades de informação e economias do conhecimento, o principal fator na criação de riqueza não é mais o de recursos naturais ou a capacidade de produção industrial, mas o conhecimento, em especial o conhecimento inovador realizado por um conjunto de profissionais criativos. Para seu desenvolvimento, cidades, regiões ou países devem adotar políticas para atrair esta «classe criativa». De acordo com Florida, então eles devem se distinguir pela alta concentração de valores que esses criadores estimam especialmente : a tolerância, o talento e a tecnologia (os três Ts do Flórida).

As afirmações do Flórida, no entanto, têm atraído críticas severas, tanto relativas as demonstrações teóricas que as articulam quanto à metodologia em que se baseiam. Primeiro, o conceito de classe criativa, a espinha dorsal da tese, ainda não está claro no discurso de Richard Florida. Ele não oferece uma definição precisa; só enumera uma lista de profissões pelo menos diversas (artistas, programadores, arquitetos, engenheiros, cientistas, professores, escritores etc.) supondo que os seus membros, que representariam mais de $30 \%$ da força de trabalho nos países desenvolvidos, têm gostos, interesses e ideias em comum, o que está longe de ser evidente. Em segundo lugar, os pesquisadores questionam seriamente a validade dos índices criados por Flórida e disputam a relação que ele postula entre os territórios e os empregos. Um de 
seus críticos mostra-se inflexível: nenhum dado empírico confirma a tese de Richard Florida. Marc Levine (2010, p.89) escreve que: "Não tem um pingo de suporte empírico para nenhum dos pressupostos centrais da teoria da classe criativa em relação ao desenvolvimento urbano".

A criatividade é um tema unificador. Em poucos anos tornouse localmente, nacionalmente e internacionalmente como um objetivo essencial das políticas públicas. Porque tanto entusiasmo? Primeiro, as políticas de criatividade são atraentes por causa de seus significados múltiplos e sua ambigüidade. As definições das indústrias criativas são muitas e imprecisas de modo que todos possam encontrar seu beneficio. Para alguns, elas mesclam com o setor das indústrias culturais. Para outros, as indústrias criativas incluem as indústrias, mas o setor é mas amplo. As políticas da criatividade surgem simultaneamente como política cultural, política econômica e política de desenvolvimento territorial. Em segundo lugar, nas nossas sociedades, a criatividade é reconhecida como um valor positivo. Diferentes grupos sociais se sentem diretamente engajados, chamados, projetam suas aspirações e seus interesses neste tipo de política. Os artistas vêem nela uma política cultural e um reconhecimento dos valores que sustentam o seu trabalho. A comunidade empresarial a vê como uma política econômica baseada na inovação e no capital humano. Eleitos municipais encontram a base de uma política territorial proativa que valoriza as atrações de sua cidade para seduzir os membros da classe criativa. Em terceiro lugar, a criatividade pode aplicar-se facilmente em diversas áreas abrangidas pelas políticas públicas. Assim, pode se tornar um alvo para os ministérios da indústria, da educação, da cultura e da Comunicação, da planificação territorial, do emprego etc.

\section{A criatividade, um novo trampolim para as estratégias políticas}

No discurso tecnocrático e político, a referência às indústrias criativas é vista como a nova esperança de dar inspiração às políticas econômicas e culturais. Exemplificada pela atitude da senhora deputada Androulla Vassiliou, Comissária Europeia 
para a Educação, Cultura, Multilinguismo e Juventude, em 23 de abril 2010: "As ICC não são apenas essenciais para a diversidade cultural do nosso continente, são também um dos mais dinâmicos setores da economia. Elas podem realmente ajudar a Europa a recuperar da crise".

Economicamente, a política de criatividade acredita na existência de um nicho de valor acrescentado, uma possibilidade de distinção dos países que carecem de recursos naturais ou padecem de decadência industrial. No plano cultural, por um lado, valoriza o papel sócioeconômico dos criadores e produtores, e por outro lado legitimiza uma abordagem comercial da cultura, destacando os valores fundamentais do trabalho artístico. Esta tendência alegra as associações artísticas que buscam valorizar a contribuição das artes e da cultura na criação de empregos e no crescimento do produto interno bruto. Estas associações, no entanto continuam a defender amargamente a autonomia da obra artística, lembrando as dificuldades de conciliar as expectativas das autoridades políticas e administrativas com a independência necessária ao exercício da livre criação.

A política da criatividade pretende à universalidade assumindo uma criatividade igual de todos os indivíduos e de todas as culturas. No entanto, tem uma importância relativa dependendo do contexto local, regional ou nacional, onde se encaixa. Na França, a referência às indústrias criativas desenvolve-se num quadro histórico de uma política econômico-cultural focalizada desde duas ou três décadas na regionalização, que assumiu recentemente as cores do desenvolvimento local. No Quebec e no Canadá, ocorre no contexto de uma política cultural e comunicacional com base na promoção e defesa da identidade e diversidade cultural.

Depois de décadas de re-regulação dos setores da cultura e da Comunicação, o que resultou numa privatização acentuada e num estreitamento do setor público, os governos estão procurando um novo papel. Neste contexto, promover a criação e a produção abre perspectivas interessantes para os gestores da coisa pública, particularmente os agentes regionais e municipais que encontramse com novas responsabilidades para o desenvolvimento regional e da cultura na sequência das diversas operações de descentralização do governo central. 
A promoção da criatividade também é um complemento natural para a defesa da diversidade cultural, o principal cavalo de batalha dos Estados-nação em matéria de cultura nos últimos anos. Notamos o impacto na Unesco que estabeleceu um "clube de cidades criativas". Ao contrario, os governos de alguns países que não assinaram o acordo sobre a diversidade cultural (EUA, Israel) também são pouco entusiasmados pelas indústrias criativas.

Os objetivos das políticas culturais mudaram ao longo do tempo, tornando-se mais e mais econômicos e industriais. No tempo de Malraux, foram destinadas principalmente para preservar o patrimônio e garantir a acessibilidade universal às atividades e as produções culturais. No Quebec, elas tiveram desde o início, o objetivo primordial da defesa da identidade nacional. Então, com a ascensão das indústrias culturais a partir da década 1970, se desviaram para promover a indústria doméstica e à proteção dos “campeões nacionais". Agora, se enfatiza a criatividade, especialmente nas cidades que se encontram com novas responsabilidades no setor da cultura, uma consequência do movimento de descentralização iniciado na década de 1980.

O desenvolvimento de uma política que valorize as indústrias criativas implica logicamente o uso de especialistas da criatividade, consultores, designers (por exemplo Flórida, Rapaille). Então, a criatividade se torna tanto uma política de Comunicação (marketing) como uma política econômica ou cultural, por meio do uso extensivo dos recursos da propaganda e das relações públicas. Em seguida, é a imagem que conta, o título de cidade criativa conferido por uma agência internacional prestigiosa, um guru da criatividade ou uma associação de cidades criativas.

Se a política de criatividade se refere à inovação tecnológica e à globalização, reconhece também implicitamente que o acesso é insuficiente para causar o desenvo'lvimento econômico, social e cultural. Isso indica uma mudança de foco desde a infra-estrutura rumo a produção de conteúdos, que é ainda uma melhoria em relação ao determinismo tecnológico da maioria das declarações políticas sobre a Sociedade da Informação. 


\section{Considerações finais: a necessidade de uma renovação do espírito crítico nas ciências da Comunicação}

Os dados de sucessivas edições do Creative Industries Mapping Document do Reino Unido e do relatório da UNCTAD (Creative Economy Report. The Challenge of Assessing the Creative Economy: towards Informed Policy making) consideram que as indústrias culturais são uma parte relativamente pequena do valor das chamadas «indústrias criativas». No caso de los documentos britânicos, o software e os serviços de computação são os motores das indústrias criativas; no caso do relatório da UNCTAD, è o design que tem o papel de motor. No entanto, a arte e a cultura estão no centro dessa construção ideológica. A evocação da criatividade permite criar pontes com as atividades culturais, cuja integração dá brilho e legitimidade a todas as indústrias criativas. Acima de tudo, a aproximação das indústrias culturais, a abrangência delas, permite reivindicar as mesmas especificidades econômicas e as mesmas intervenções de proteção que as autoridades públicas tenham implantado ao longo dos anos em áreas artísticas e culturais.

A noção de criatividade também se refere à inovação, valor fundamental das teorias sobre a Sociedade da Informação, que constituem o quadro geral de interpretação dominante da mudança social em curso. Se a operação parece proporcionar aos artistas e produtores culturais um estatuto privilegiado nessas sociedades do conhecimento, é apenas o fruto de alguns mal-entendidos, pois a criatividade e inovação no pensamento de ideólogos, tecnocratas e políticos são muito mais da ordem científica e técnica que da ordem das artes e da cultura.

A operação ideológica, em seguida, apresenta toda a aparência de coerência. Mas do ponto de vista científico, qual é a contribuição desta abordagem? Uma análise rigorosa não tarda em mostrar a fragilidade da construção ideológica. No plano teórico, o conceito de indústrias criativas não contribui absolutamente nada aos estudos sobre as indústrias culturais. Ja se reconhecia a importância da criação na produção cultural. E a extensão dos modelos desenvolvidos para explicar as especificidades da produção e difusão cultural para outras atividades (como o design, a moda 
ou o software) não é estabelecida de forma convincente. Assim, devemos fazer uma demonstração antes de extender as mesmas medidas públicas de protecção e promoção das indústrias culturais.

Talvez fosse útil e proveitoso considerar a distribuição de determinadas características peculiares aos setores culturais para a economia em que vivem, como sugerimos em 1997. Mas uma tal operação exigiria ir além duma rotulagem simples e fazer uma rigorosa análise de condições para a criação, produção e divulgação. Os defensores das indústrias criativas não parecem interessados em tais pesquisas.

Do ponto de vista empírico, a literatura sobre as indústrias criativas é pouco convincente. Entra com certeza uma parte relativamente criativa numa variedade de atividades econômicas. Porque escolher umas mais que outras? Os critérios de seleção não são explícitos, as definições são vagas e fornecem poucos dados para avaliar o valor econômico real de criatividade nos setores selecionados.

Alguns aplaudirão a substituição das indústrias criativas as indústrias culturais e tambem a proposta para expandir a intervenção do governo a novas áreas de atividades relacionadas com a digitalização. Na extensão da lógica própria as indústrias culturais aos setores mais dinâmicos da economia, baseados no uso das tecnologias digitais, eles vão ver uma «culturalização» da economia, uma volta da política, o fim de uma visão meramente «economicista» dos assuntos humanos. Apresentados como modelos, as indústrias culturais veriam seu papel na sociedade reconhecido, a sua contribuição econômica valorizada, o apoio do Estado fortalecido. A criatividade, dizem seus promotores, é a imaginação no poder. Esta hipótese, baseada por um lado numa aceitação acrítica de resultados duvidosos metodologicamente acima mencionada, postula pour outro lado um consenso ideológico que não existe. Quanto ao papel do Estado, o documento da UNCTAD é o oposto do Documento de Mapeamento do Reino Unido. Enquanto o primeiro refere-se aos argumentos de bens meritosos e de serviço público, o segundo apenas reitera a importância da educação e o respeito dos direitos de autor.

De outro ponto de vista, a amálgama das indústrias culturais e das indústrias "criativas" esconde um perigo potencial, o de 
diluir a especificidade das indústrias culturais e de enfraquecer o argumento em favor da intervenção do Estado. As noções de serviço público e de bens de mérito, por exemplo, já abalada por décadas de neoliberalismo, enfrentam o perigro de perder toda credibilidade por extender-se a áreas como a moda e os vídeogames. Desacreditados com reivindicações não justificadas, se tornaria mais difícil de usar esses argumentos para legitimizar a intervenção estatal nas areas da radiodifusão, das artes e dos serviços culturais. No reverso, a visão estritamente utilitarista da criatividade que aparece na literatura sobre as indústrias criativas, a que se traduz necessariamente na criação de empregos e de produção de lucros, pode contaminar vários programas de apoio as artes e a cultura. Em suma, tudo isso pode resultar numa maior integração das indústrias culturais à lógica capitalista ao invés de uma problematica "culturalização" da economia.

Para terminar, a renovação do pensamento crítico nas ciências da Comunicação parece ser mais importante que em outras áreas porque a persuasão e a manipulação são fenômenos de Comunicação, integrantes de nosso objeto de conhecimento. Acertando que o pensamento crítico não é inimigo da criatividade, acabo com uma citação do grande poeta francês Charles Baudelaire: "Tous les grands poètes deviennent naturellement, fatalement, critiques" (Todos os grandes poetas se tornam naturalmente, fatalmente, críticos).

Porém, não esqueçamos que é arriscado ser criativo. Muitas vezes se encontra com a incompreensão e a recusa. Também, muitas vezes é perigoso se mostrar crìtico. Não é o caminho mais facil rumo ao successo. Ser criativo e crítico ao mesmo tempo, muitas vezes é a melhor receita para o fracasso, a corto prazo. Porem, a largo prazo, é a estrada da verdade e do progresso.

\section{REFERÊNCIAS}

BUSTAMANTE, Enrique. De las industrias culturales al entretenimiento, la creatividad, al innovación... Viejos y nuevos señuelos para la investigación de la cultural. Dia-Logos, 2009.

FLORIDA, Richard. The Rise of the Creative Class. And how it's transforming work, leisure and everyday life, Basic Books, 2002. 
GARNHAM, Nicholas. From Cultural to Creative Industries. An analysis of the implications of the 'creative industries' approach to arts and media policy making in the UK. In : INTERNATIONAL JOURNAL OF CULTURAL POLICY. (11) 1, 2205.

KUHN, Thomas. The Structure of Scientific Revolutions. Chicago: University of Chicago Press, 1957.

LACROIX, Jean-Guy; TREMBLAY, Gaëtan. The Information Society and the Cultural Industries Theory. Current Sociology Trend Report. London: Sage Publications, 1997.

LEVINE, Marc V. La classe créative et la prospérité urbaine. Mythes et réalités. In: La classe créative selon Richard Florida. Un paradigme urbain plausible?, sous la direction de Rémy Tremblay et Diane-Gabrielle Tremblay. Québec: Presses de l'université du Québec, 2010.

ROY-VALEX, Myrtille. Arts, territoires et 'nouvelle économie' : quelles perspectives ouvertes par la théorie du capital créatif? In: La classe créative selon Richard Florida. Un paradigme urbain plausible?, sous la direction de Rémy Tremblay et Diane-Gabrielle Tremblay. Québec : Presses de l'université du Québec, 2010.

SCHLESINGER, Philip. Creativity: from discourse to doctrine? Screen, (48) 3, 2001.

TREMBLAY, Gaëtan, Creative Statistics to Support Creative Economy Politics. Media, Culture and Society. No prelo.

- Desde la teoría de las industrias culturales: Evaluación crítica de la economía de la creatividad. In : BUSTAMANTE, Enrique (ed.). Las industrias creativas. Polémica sobre una moda polifacetica. Gedisa, à paraître 2001.

- Industries culturelles, économie créative et société de l'information. In: GLOBAL MEDIA JOURNAL. Canadian Edition, (1), 1, 2008. Disponível em: www.gmj.uottawa.ca/0801/inaugural f.html

TREMBLAY, Gaëtan; TREMBLAY, Diane-Gabrielle. La classe créative selon Richard Florida. Un paradigme urbain plausible? Québec : Presses de l'université du Québec, 2010.

UNITED NATIONS Conference on Trade and Development. Creative Economy Report. The Challenge of Assessing the Creative Economy: towards Informed Policy making, 2008. Disponível em: www.unctad.org/en/docs/ ditc20082cer_en.pdf 